Vos, H.M.M., Adan, I.M.A., Schellevis, F.G., Lagro-Janssen, A.L.M. Prevention in primary care: facilitators and barriers to transform prevention from a random coincidence to a systematic approach. Journal of Evaluation in Clinical Practice: 2014, 20(3), 208-215

\begin{tabular}{|l|l|}
\hline $\begin{array}{l}\text { Postprint } \\
\text { Version }\end{array}$ & 1.0 \\
\hline Journal website & http://onlinelibrary.wiley.com/doi/10.1111/jep.12108/abstract \\
\hline Pubmed link & http://www.ncbi.nlm.nih.gov/pubmed/24330278 \\
\hline DOI & 10.1111/jep.12108 \\
\hline
\end{tabular}

This is a NIVEL certified Post Print, more info at http://www.nivel.eu

\title{
Prevention in primary care: facilitators and barriers to transform prevention from a random coincidence to a systematic approach
}

\author{
Hedwig M. M. Vos MD General Practitioner, PhD StUdent ${ }^{1, *}$, Iris M. A. AdAN BSC \\ STUDENT ASSISTANT ${ }^{1}$, FRANÇOIS G. SCHELLEVIS MD PHD PROFESSOR, DOCTOR ${ }^{2,3}$, \\ ANTOINE L. M. LAGRO-JANSSEN MD PHD PROFESSOR, DOCTOR ${ }^{1}$
}

\section{Abstract}

Rationale, aims and objectives: The Dutch general practitioner (GP) plays a substantial role in prevention. At the same time, many GPs hesitate to incorporate large-scale cardiovascular risk management (CVRM) programmes into their daily practice. By exploring facilitators and barriers occurring during the past three decades, we wish to find clues on how to motivate professionals to adopt and implement prevention programmes.

Methods: A witness seminar was organized in September 2011, inviting key figures to discuss the decision-making process of the implementation of systematic prevention programmes in the Netherlands in the past, thereby adding new perspectives on past events. The extensive discussion was fully audiotaped. The transcript was content-analysed.

Results: We came across four different transitional stages: (1) the conversion from GPs disputing prevention to the implementation of systematic influenza vaccination; (2) the transition from systematic influenza vaccination to planning CVRM programmes; (3) the transition from planning and piloting CVRM programmes to cancelling the large-scale implementation of the CVRM programme; and (4) the reinforcement of prevention.

Conclusions: The GPs' fear to lose the domain of prevention to other health care professionals and financial and logistical support are the main facilitators for implementing prevention programmes in primary care. The main barriers for implementing prevention are the combination of insecurity about reimbursement and lack of scientific evidence. It appears that the ethical view of GPs that 
Vos, H.M.M., Adan, I.M.A., Schellevis, F.G., Lagro-Janssen, A.L.M. Prevention in primary care: facilitators and barriers to transform prevention from a random coincidence to a systematic approach. Journal of Evaluation in Clinical Practice: 2014, 20(3), 208-215

everyone should have the same right to obtain preventive care gradually takes over the inclination to hold on to evidence-based prevention.

\section{INTRODUCTION}

Over the past decades, elements of population-based preventive care have gradually been introduced in general practice, which is traditionally characterized by an individually centred curative approach. One might conclude that primary care is in a transition from the individually centred care of the 20th century to a more population-orientated care in the 21st century. An important motive for incorporating prevention of diseases in healthy people into primary care is the necessity of integrating prevention and cure [1,2]. If there is a relation between disease prevention and the patient's current state of health, the patient's compliance with follow-up advice may be stimulated [2].

In the Netherlands, as in many other countries, the general practitioner (GP) has the best access to individuals at risk because all Dutch citizens are registered with a general practice, and approximately 75\% visit their GP at least once a year [3]. Moreover, GPs keep medical records of all listed patients.

In 1995, the Ministry gave a grant to implement the project 'Prevention: tailormade'. In the framework of this project, GPs have been supported in organizing and implementing influenza vaccination ever since 1997. In the same year, the organization of cervical cancer screening by GPs became a reality [2].

Nowadays, the Dutch GP appears to be increasingly motivated to perform preventive actions in primary care and has been playing an ever-enlarging role in the systematic influenza vaccination and cervical cancer screening in the Netherlands. At the same time, we see that many GPs still hesitate to incorporate other selective prevention programmes such as the third step of 'Prevention: tailor-made', cardiovascular risk management (CVRM), into their daily practice.

Changes in clinical practice are only partly within doctors' control. Obstacles to change are generally not only in the professional setting but also in the patient, the organization of care processes, resources, leadership or the political environment [4]. The translation of identified barriers into tailor-made implementation interventions is still a black box. Structural barriers to the successful implementation of change interventions should therefore be deliberately sought, preferably from the perspectives of different stakeholders in the care process, and as objectively as possible [5].

It is therefore relevant to know how decision making and implementation of prevention programmes came about and to describe this change process, including facilitators and barriers in a historical perspective. This can provide clues for how to motivate professionals to implement selective prevention programmes into their daily practice. Our research question was: What were the facilitators and barriers in the process of implementing prevention in primary care over the past three decades? Our main focus was the implementation of CVRM, but we started our discussion with all prevention programmes.

In the Netherlands, two associations of GPs are active: one covering the professional interest (association) and the other the scientific basis for the profession (college). More than $90 \%$ of the GPs is a member of both organizations. With regard to prevention, they broadly overlap each other. For reasons of clarity, we therefore talk 
Vos, H.M.M., Adan, I.M.A., Schellevis, F.G., Lagro-Janssen, A.L.M. Prevention in primary care: facilitators and barriers to transform prevention from a random coincidence to a systematic approach. Journal of Evaluation in Clinical Practice: 2014, 20(3), 208-215

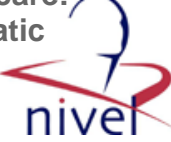

about associations of GPs, or when the difference between the organizations needs to be emphasized, we use the terms 'association' and 'college'.

\section{METHODS}

\section{Witness seminar}

We used a qualitative approach in a witness seminar to answer our research question. This method was developed by the Institute of Contemporary British History as a special type of oral history in which experts, researchers and policy makers are invited to meet in order to explain and debate their recollections of a particular subject at a certain period in time [6]. This enables researchers to elaborate on developments in the past. The advantage of using this method to investigate the subject of prevention in primary care in the Netherlands is that it may generate a better understanding of aspects that were relevant in the process of debating and implementing prevention from the viewpoint of different stakeholders.

\section{Study sample}

By means of published literature and recollections of several GPs who were involved in the prevention debate, we identified potential witnesses. They had been either involved as board members of the Dutch GP associations, primary care policy or scientific research or had been particularly involved in the prevention debate. Eighteen witnesses who were involved in the past discussions and decision-making processes were invited personally, by e-mail and/or by letter to participate. Ten of them consented to join the discussion. As three of them had to cancel for logistical reasons, seven participants attended the seminar. The meeting was chaired by an independent chairperson. The meeting was introduced outlining the historical events in order to activate the memories of those attending the seminar. One interview with an additional witness was performed by telephone afterwards to check details that came up during the seminar.

\section{Analysis}

The 3-hour meeting took place in September 2011 and was fully recorded. Three researchers (HV, IA and FS) were present as observers. The entire discussion was transcribed verbatim. The transcript was checked for completeness and accuracy by comparing the typed and audiotaped versions. A full copy of the transcript was sent to all participants for correction. Amendments were only allowed for matters of style or for mistakenly remembered facts such as names or dates. The quotes were translated from Dutch into English.

The transcript was independently analysed. Consistency and inter-coder agreement were obtained by analysing and discussing the codes by two of the researchers (HV and IA) and after that, by discussing and creating a theory by three of the researchers (HV, FS and AL). The key points were marked with a series of codes, which were extracted from the text. The codes were grouped into similar concepts, and the concepts were grouped into categories. The central themes identified were divided into facilitators and barriers to the implementation of prevention. The facilitators and barriers will be presented based on the implementation process of prevention divided in four stages of transition. These transitional moments were characterized by a 
Vos, H.M.M., Adan, I.M.A., Schellevis, F.G., Lagro-Janssen, A.L.M. Prevention in primary care: facilitators and barriers to transform prevention from a random coincidence to a systematic approach. Journal of Evaluation in Clinical Practice: 2014, 20(3), 208-215

change in the relation between facilitating and impeding factors and/or an important contextual event or decision. This process of implementation will be described according to the facts mentioned during the seminar and will be illustrated by quotes. All identified codes were grouped into four main categories: (1) social context; (2) professional context; (3) organizational context; and (4) personal motives. This classification is according to a theoretical perspective of Oxman and Flottorp [7], completed with personal motives.

\section{RESULTS}

The witnesses discussed the implementation of systematic influenza vaccination to provide an example of the discussion on the implementation of prevention in primary care. Gradually, the chairman shifted the focus to CVRM to describe the process following the implementation of systematic influenza vaccination. The implementation of cervical cancer screening was disregarded during the seminar for this did not seem to represent a major topic for discussion in the Netherlands. Table 1 shows the characteristics of the witnesses.

\section{[TABLE 1]}

We came across four different transitional stages.

\section{Stage 1: The introduction of prevention in primary care (roughly 1985-1993)}

The first stage comprises the conversion from GPs disputing prevention to GPs being persuaded by the associations of GPs to implement the systematic administration of influenza vaccinations in their practice. Table 2 shows the facilitators and barriers characterizing this stage.

During the mid-1980s, a substantial part of Dutch GPs had no intention to implement prevention tasks in their daily work as they regarded prevention as not falling within their remits. The arguments made by Wilson and Jungner in the World Health Organization document 'Principles and practice of screening for disease' were used as arguments [8].

\section{[TABLE 2]}

[...] We saw, very typical, as usual, the dialogue or rather the non-dialogue of the socalled pioneers or evangelists and the skeptics. This has been going on all the time. And these kind of undulations have, as I stated there very vigorously, very much to do with the fact that the advertisement [for prevention] is much larger than what it brings about. That is the scientific part of what they say, that it works so well, but look at the evidence: very poor. (Participant 1)

Over the next couple of years, prevention projects started in the context of scientific research. The majority of the members of the associations of GPs still voted against the implementation of influenza vaccination in general practice, with the main argument that curative care, and not prevention, was the core business of the GP. 
Vos, H.M.M., Adan, I.M.A., Schellevis, F.G., Lagro-Janssen, A.L.M. Prevention in primary care: facilitators and barriers to transform prevention from a random coincidence to a systematic approach. Journal of Evaluation in Clinical Practice: 2014, 20(3), 208-215

Then we used a tactical maneuver to get it accepted: "Let's vaccinate for one year, supported, well paid, you will be supported by one of the districts, all you have to do is vaccinate, so to speak. One year, give us one year”. (Participant 2)

A 1-year implementation-pilot was agreed. An argument for the associations' board to propose to implement systematic influenza vaccination was the positioning of the GP in the centre of the field of prevention.

I think there was a defensive strategy present as well to enlarge the task of the GP. [...] But also an ideological argument. (Participant 2)

The board was aware that the only way to get prevention programmes implemented was by guaranteeing financial support. When the pilot was evaluated after one year, a large majority of the GPs wanted to proceed.

I still remember his name. He stood up and said: "It's not our job as GPs", I remember. But than two others stood up and said: "We've never made this much money in one afternoon, so shut up!”. (Participant 2)

In the early 1990s, it turned out that many professionals intended to take up influenza vaccination.

It appeared that everyone wanted to pick it up: the Municipal Health Services wanted to do it, the pharmacists made very good money with it. (Participant 3)

What argued in favour of the GPs were the electronic information systems that were already being used in primary care, tailor-made for identifying people at high risk. The government believed that the vaccination level could be improved if GPs were more involved. Prevention policy turned out to be an important vehicle for showing ambition, and a joint annotation of the associations of GPs was requested by the Minister of Health. Interference from the Ministry of Health did not go beyond financing the influenza vaccination, education and publicity.

Yes, in our opinion it has always been like that when the profession does its job, then we generally don't have to interfere that much. [...] So financially, the Ministry of Health encouraged it. But it originated totally from the organizations of GPs.

(Participant 4)

The scientific evidence base for influenza vaccination, however, was not very strong. Today I regard it as a kind of mark on my soul, like, you did not have to allow this to happen. [...] In my opinion the influenza vaccination program should never have passed for scientific reasons. (Participant 1)

Others were critical as well.

Fifty-seven percent degree of protection. Immensely low. I always say wherever I come that we have a frigging vaccine, which is the truth, but because we vaccinate so many people it's in an absolute way still something you have to trust. [...] I wasn't there when the board said that they had to follow a guideline, but I kept calling for one of course. Why? Because my PhD research subject assumed a guideline and otherwise there was none. (Participant 3)

The GP guideline on influenza vaccinations was authorized in 1993. The evidence available in those days was considered sufficient by the associations of GPs.

In conclusion, the implementation of systematic influenza vaccination in general practice turned out to be successful in this stage because the main facilitators (the fear to lose the domain of prevention to other health care professionals and financial and logistic support) gradually prevailed over the main barriers (lack of scientific evidence and the opinion of GPs that prevention is not falling within their remits). 
Vos, H.M.M., Adan, I.M.A., Schellevis, F.G., Lagro-Janssen, A.L.M. Prevention in primary care: facilitators and barriers to transform prevention from a random coincidence to a systematic approach. Journal of Evaluation in Clinical Practice: 2014, 20(3), 208-215

The success of the implementation is demonstrated by increasing vaccination levels (from 28\% in 1991 to $74 \%$ in 2007, after this year, the levels stabilized) [9].

\section{Stage 2: So far, so good: from influenza vaccination to planning and piloting CVRM (1993-1999)}

The second stage comprises the transition from systematic influenza vaccination to discussing and even planning and piloting CVRM programmes. Table 3 shows the facilitators and barriers characterizing the second stage.

\section{[TABLE 3]}

In 1995, the associations of GPs launched the 'Prevention: tailor-made' programme. The implementation of influenza vaccination and cervical cancer screening proved to be successful. The need to combine the pre-existing guidelines on hypertension and hypercholesterolemia into one guideline, together with the presence of ICT facilities in primary care to identify high-risk people, were arguments for the GP associations to choose CVRM next.

[The fact that others would pick this up] was not an argument. [...] When high-risk people need to be identified GPs are the only ones who can do this, owing to the data in their medical records. (Participant 5)

Scientific arguments were present as well. Trials were already performed to test the effects of cardiovascular disease (CVD) prevention performed by the practice nurse. Lastly, available funding was an important argument for choosing CVRM as a focus point for prevention.

[The choice for CVD] I think [...] had to do with the fact that the trials were very easily funded by the Dutch Heart Association, which was of course a very rich club. (Participant 6)

In 1996, the associations of GPs insisted on the support of a practice nurse within the practice in order to implement the CVRM programme properly.

We picked it up but it took us, the board, the next three, three and a half, almost four years to obtain actual support within the practice. (Participant 2)

This was facilitated by an increase of the capitation fee and fee for service.

Arguments about prevention not being the task of the GP were degraded by the discussion whether CVRM was prevention or rather an improvement of quality of care.

It was about a better treatment for people who were already included under care. This was true for diabetes, but also for hypertension. For years, then, this was the most important portal for discussing CVD altogether. In those days, it was about secondary prevention [...]. This is an improvement of existing care, which is really not so bad. (Participant 1)

The identification of people at high risk had already been described in the existing guidelines on hypertension and hypercholesterolaemia. In planning the CVRM programme, the funder of the programme insisted on continuing to measure blood pressure in all people of 60 years and over, as was already described in the guideline on hypertension, forcing the implementation of a screening programme on people whose risk was unknown.

That in-depth discussion [of available evidence for the reduction of morbidity by prevention] was never held in our group, because the guidelines were the starting 
Vos, H.M.M., Adan, I.M.A., Schellevis, F.G., Lagro-Janssen, A.L.M. Prevention in primary care: facilitators and barriers to transform prevention from a random coincidence to a systematic approach. Journal of Evaluation in Clinical Practice: 2014, 20(3), 208-215

point, and these guidelines implied that there was evidence for treating or advising people with high risk of CVD. (Participant 5)

At the end of the 1990s, 1000 of the 8000 Dutch GPs participated in a CVRM pilot programme. In the same period, however, a discussion on income and supporting personnel started in the GP associations.

In conclusion, planning and piloting the CVRM programmes in general practice turned out to be successful in this stage because the positive arguments concerning the present scientific evidence outweighed the negative arguments. Moreover, GPs had a stable position in health care politics illustrated by governmental support, by means of an increase of the capitation fee and fee for service. This governmental support created, but also resulted from, a stable position of the Dutch GP.

\section{Stage 3: When pilots become policy, political tensions break out (1999-2000)}

The third stage is characterized by the transition from planning and piloting CVRM programmes to cancelling the CVRM prevention project. Table 4 shows the facilitators and barriers characterizing the third stage.

\section{[TABLE 4]}

When pilots were to become policy, the barriers started to outweigh the facilitators. At the end of the 1990s, discussions on GPs' wages caused an uproar. It was a booming time when they said: "The lawyer with whom I graduated makes six times more money than I do". (Participant 2)

The board of the association of GPs insisted on employing practice nurses in prevention programmes. An agreement with the Minister of Health was signed in 1999. But tensions ran even higher, both in the board and in the profession.

The board [of the college of GPs] insisted on proceeding, on the condition that more research should be done on the effectiveness of screening people for CVD risks over the age of 60. (Participant 5)

In spite of actions to influence the opinion forming process such as publications in the Dutch Journal of the Medical Association, distrust and insecurity whether practice support would be implemented and financial motives led to the cancellation of the large-scale implementation of the CVRM programme at an association members' meeting in 2000.

GPs were irritated with the Ministry of Health, and throwing out the programme was a way to show their irritation.

What I also heard from people within [the college] is that this item was on the agenda of that members' meeting quite by chance. Had this item been on the agenda two months later, and had a mental health project been on the agenda at this meeting, then this [mental health] project would have been thrown out. (Participant 5) In response to the situation, the Ministry regarded that more funding for CVRM was not on the agenda. The Ministry of Health stated that they had already made an effort to obtain sufficient financial support for employing practice nurses. This led to a trench warfare between the Ministry of Health and the GPs. The college was aware of the climate of agitation of the GPs, but could not provide sufficient scientific evidence to contradict the financial arguments. 
Vos, H.M.M., Adan, I.M.A., Schellevis, F.G., Lagro-Janssen, A.L.M. Prevention in primary care: facilitators and barriers to transform prevention from a random coincidence to a systematic approach. Journal of Evaluation in Clinical Practice: 2014, 20(3), 208-215

In my opinion [...], for prevention we need calmness in the profession. Then GPs are certainly willing to listen to good arguments for performing prevention programs. Adequate financial compensation is also required. (Participant 2) In conclusion, the actual implementation of the CVRM programmes in general practice was not successful in this stage because of the main barriers in this stage, being discontent about income among GPs, agitation in the profession towards the Ministry of Health because of insecurity about financial and logistic support. Moreover, scientific evidence and the facilitators that were present appeared to be insufficient as a counterbalance.

\section{Stage 4: Let's start all over again ... (2000-present)}

The fourth stage was characterized by the transition from cancelling the CVRM programme to enforcing prevention via the introduction of a so-called Prevention Consultation. Table 5 shows the facilitators and barriers characterizing the last stage.

\section{[TABLE 5]}

After the CVRM programme had been cancelled, a quarrelsome atmosphere lingered for years, mainly targeting the Ministry of Health.

And we just proceeded with the revision of the evidence based GP guidelines. [...] It was decided to update and to cluster the guidelines on separate CVD risk factors into one guideline. (Participant 7)

Prevention, however, was not on the agenda.

[Cancelling "Prevention: tailor-made"] was perceived as a defeat, [...], but the foundation and benefit of the whole project remained intact. So if we could bring it back in another way, by updating the cardiovascular guidelines for instance, then that would still be a good thing. (Participant 3)

In these years, all kinds of initiatives were taken outside primary care, such as health checks offered by commercial companies.

What happened was that those health funds and other suppliers of checkups assumed that they would trace people, that they would measure all kinds of things, that those people would obviously go to their GP if anything was wrong and that those guidelines would then become effective. (Participant 5)

GPs and the media turned to the college of GPs for its opinion. The college formulated a position paper on medical checks for healthy people. The Kidney Foundation, The Diabetes Fund and the Dutch Heart Foundation together took it much farther and requested a guideline on screening for CVD risk.

On the basis of the principle of equity everyone should have the same right to obtain this kind of care and right now it is just an absolute coincidence. (Participant 3) Eventually, a study group of GPs together with experts from the funds started working together to look for evidence for screening. This led to the Prevention Consultation guideline, including a method for screening of people who had no known risk for CVD and to identify people at high risk. When the Prevention Consultation guideline was authorized, a so-called disclaimer was published as well, saying that, although the guideline had been approved, the evidence for actively approaching possible high-risk patients was still insufficient.

It hasn't been proven yet, cost-effectiveness has to be researched, but at this moment I think you cannot miss this opportunity. (Participant 8) 
Vos, H.M.M., Adan, I.M.A., Schellevis, F.G., Lagro-Janssen, A.L.M. Prevention in primary care: facilitators and barriers to transform prevention from a random coincidence to a systematic approach. Journal of Evaluation in Clinical Practice: 2014, 20(3), 208-215

A shift in the interpretation of evidence based, from proven effectiveness to the best evidence available, together with social and professional developments prompted the college of GPs to publish the guideline Prevention Consultation to catch the opportunity.

In 2006, a new system of health care insurance was introduced based on risk equalization, and market forces entered the Dutch health care system. Private health insurance companies were assigned to regulate health costs in the Netherlands. The associations of GPs hoped that the insurance companies would incorporate prevention in primary care by GPs in their insurance package, instead of prevention activities by other stakeholders.

But you won't be surprised to hear that for many health insurance companies prevention is a marketing activity, and not at all an activity to keep their policyholders healthier. (Participant 7)

The GPs were under the impression that the Prevention Consultation would be covered as part of the basic insurance package, but this was not the case.

Ever since 2006 there will never be quietness in the world of healthcare. The GP is pragmatic, so he will find his way. Scientifically powered, but he also has to think about his wallet. (Participant 2)

In conclusion, although the main facilitators in this phase (the availability of various health checks from other parties that prompted the GPs to offer their own check-ups and the perceived responsibility to offer prevention for all people at high risk on the basis of the principle of equity) led to the development of the Prevention Consultation guideline, eventually the implementation of prevention programmes in general practice was not successful in this stage because financial compensation offered by health insurances was insufficient.

\section{DisCUSSION}

We found that in all stages, similar facilitators and barriers played a role, and in all stages, financial support played a pivotal role. It appeared that facilitating elements, such as the fear of losing the domain of prevention to other health care professionals, political pressure, unity within GPs, and the opinion that prevention is effective, fair and corresponds with daily practice and the principle of equity motivated GPs to take actions in order to introduce prevention, but finances turned out to be a prerequisite for actual implementation.

When other stakeholders tend to take up tasks that are also allocated to general practice, GPs appear to have a strong tendency to pro-actively appropriate more power to themselves, which makes this threat of the domain of primary care an important motivational incentive. We also conclude that gradually the importance attached to evidence diminishes and proven effectiveness is no longer the main motive to pick up prevention. This can either be explained by the fact that evidence on prevention is harder to obtain than evidence on cure. But we also notice that the professional opinion about equity plays a pivotal role for many GPs to take up prevention. The discussion on social health inequities in the Netherlands might have contributed to this shift in opinion.

We found that the main barriers for implementing prevention are the insecurity about financial and logistical support, insufficient scientific evidence, the opinion of GPs that prevention is not falling within their remits, agitation among GPs and friction 
Vos, H.M.M., Adan, I.M.A., Schellevis, F.G., Lagro-Janssen, A.L.M. Prevention in primary care: facilitators and barriers to transform prevention from a random coincidence to a systematic approach. Journal of Evaluation in Clinical Practice: 2014, 20(3), 208-215

between the professional organizations with each other and with the Ministry of Health. In the four different stages, all categories of arguments had a different impact leading to a positive or a negative view on prevention by GPs and therefore leading to a successful or not successful implementation of prevention programmes. But insecurity about finances provided by the government and/or health care insurance companies gradually becomes definitely the main motive for GPs to vote against prevention or to hesitate to implement prevention.

\section{Comparison with existing literature}

Major difficulties arise when introducing clinical guidelines into routine daily practice. Even if doctors are aware of the evidence and are willing to change, to alter well-established patterns of care is difficult. Analyses of barriers to changing practice have shown that obstacles can arise at different stages in the health care system [10]. We identified a social context, a professional context, an organizational context and personal motives.

To persuade GPs into taking up preventive actions, a number of requirements have to be met. The first prerequisite is financial and logistical support because of the increasing workload. We found that financial and logistic support stimulated the implementation of systematic influenza vaccination. This was also concluded in implementing type II diabetes guidelines in general practice [11]. Huy et al. found that better financial and organizational conditions are facilitators to improve the provision of preventive care in CVRM [12].

In our discussion, scientific evidence turned out to be an important prerequisite and at the same time a continuous cause for debate. But even when evidence is present, this will not automatically lead to a better quality of care. The emergence of evidence-based medicine has not automatically been very successful in improving the quality of care [13]. Both in the implementation of influenza vaccination as CVRM programmes, scientific evidence was not fully present when prevention programmes started. In this light, personal motives and coincidences need to be taken into account when implementing a prevention programme.

\section{Strengths and limitations of the study}

We chose a qualitative approach owing to the sparse literature about the debate and implementation process of prevention programmes in primary care. The strength of a witness seminar is that interaction between the members can contribute to exploring and clarifying individual opinions. Concurrently, the interaction in the group can introduce new issues to the interview, enabling new themes or aspects to materialize [14].

Our results are based on a witness seminar with a group of people with different backgrounds, both GPs and other officials. Seven of eighteen invited participated. We are convinced that those who volunteered to the seminar were the main key players in the debate about prevention. This assumption was confirmed during the seminar. During the seminar and afterwards when analysing our data, we found that the witnesses were able to cover the whole period of time we aimed to study. Moreover, many of the facts mentioned during the seminar were confirmed by scientific primary care publications during those periods. 
Vos, H.M.M., Adan, I.M.A., Schellevis, F.G., Lagro-Janssen, A.L.M. Prevention in primary care: facilitators and barriers to transform prevention from a random coincidence to a systematic approach. Journal of Evaluation in Clinical Practice: 2014, 20(3), 208-215

\section{Recommendations for future research and implementation}

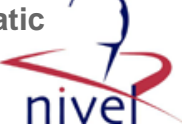

We recommend that prevention in primary care must be encouraged by reserving money for prevention within a population-based budget and by working together with the local government and Municipal Health Services and other stakeholders to improve the health of a population. Health insurance companies should be made responsible for prevention as well, translating in a separate and sufficient budget for prevention, at greater length, to create space to develop preventive activities in primary care. We recommend more quantitative and qualitative research to study attitude and readiness to implement prevention in primary care, and lastly, we recommend more research to study evidence for prevention and screening, both for health parameters and for cost-effectiveness.

We found these facilitators and barriers in the Netherlands, but our results can inform and support future approaches to implement prevention in primary care in other countries as well. We recommend comparable research in other countries with different health care systems to find out to what extent the facilitators and barriers we found are specific for the Netherlands and for the Dutch health care system.

\section{CONCLUSION}

Over the years, prevention has more and more become the domain of primary care not only due to political pressure but also due to social needs for screening. GPs' fear of losing the domain of prevention to other health care professionals, and financial and logistical support are the main facilitators for the implementation of prevention programmes in primary care and financial support plays a pivotal role. Insecurity about reimbursement and lack of scientific evidence are the main barriers. Evidence seems to become less important, and it appears that the ethical view of GPs that everyone should have the same right to obtain preventive care gradually takes over the inclination to hold on to evidence-based prevention.

\section{CONFLICT OF INTEREST}

The witness seminar was funded by the Hilly de Roever-Bonnet fund of the Association of Dutch female doctors (VNVA). The sponsor had no role in designing the seminar, or subsequent analysis of data, or decisions about publication. There are no financial or personal relationship issues that might bias the study.

The authors declare no conflict of interests. The authors alone are responsible for the content and writing of this paper.

\section{ACKNOWLEDGEMENTS}

We are very grateful to all the witnesses and the chairman who help to create the comfortable atmosphere in which memories could be shared. 
Vos, H.M.M., Adan, I.M.A., Schellevis, F.G., Lagro-Janssen, A.L.M. Prevention in primary care: facilitators and barriers to transform prevention from a random coincidence to a systematic approach. Journal of Evaluation in Clinical Practice: 2014, 20(3), 208-215

\section{REFERENCES}

1 Assendelft, W. J. J., Nielen, M. M. J., Hettinga, D. M., Van der Meer, V., Van Vliet, M., Drenthen, A. J. M., Schellevis, F. G. \& Van Oosterhout, M. J. W. (2012) Bridging the gap between public health and primary care in prevention of cardiometabolic diseases; background of and experiences with the prevention consultation in the Netherlands. Family Practice, 29, i126-i131.

2 Drenthen, T. (1997) Challenges to prevention in Dutch general practice. The American Journal of Clinical Nutrition, 65 (6 Suppl), 1943S-1945S.

3 Smits, F. T. M., Mohrs, J. J., Beem, E. E., Bindels, P. J. E. \& Van Weert, H. C. P. H. (2008) Defining frequent attendance in general practice. BMC Family Practice, 9, 21.

4 Ferlie, E. B. \& Shortell, S. M. (2001) Improving the quality of health care in the United Kingdom and the United States: a framework for change. The Milbank Quarterly, 79, 281315.

5 Bosch, M., van der Weijden, T., Wensing, M. \& Grol, R. (2007) Tailoring quality improvement interventions to identified barriers: a multiple case analysis. Journal of Evaluation in Clinical Practice, 13, 161-168.

6 The Institute of Contemporary British History (ICBH) (2013) Oral History Programme [online]. Available at: http://www.kcl.ac.uk/innovation/groups/ich/witness/index.aspx (last accessed 10 April 2013).

7 Oxman, A. \& Flottorp, S. (2001) An overview of strategies to promote implementation of evidence-based health care. In Evidence-Based Practice in Primary Care (eds C. Silagy \& A. Haines ), 2nd edn, pp. 101-119, London: BMJ Books.

8 Wilson, J. M. G. \& Jungner, G. (1986) Principles and Practice of Screening for Disease. Geneva: World Health Organization.

9 Heijnen, M. L. (2008) Influenza: Wat is het bereik? In Volksgezondheid Toekomst Verkenning, Nationaal Kompas Volksgezondheid. Bilthoven: RIVM. Available at: http://www.nationaalkompas.nl/preventie/van-ziekten-en-aandoeningen/influenza/bereik/ (last accessed 6 December 2013).

$10 \mathrm{Grol}, \mathrm{R}$. \& Grimshaw, J. (2003) From best evidence to best practice: effective implementation of change in patients' care. Lancet, 362, 1225-1230.

11 Meulepas, M. A., Braspenning, J. C. C., de Grauw, W. J., Lucas, A. E. M., Harms, L., Akkermans, R. P. \& Grol, R. P. T. M. (2007) Logistic support service improves processes and outcomes of diabetes care in general practice. Family Practice, 24, 20-25.

12 Huy, C., Diehm, C. \& Schneider, S. (2012) Cardiovascular prevention at the general practitioner? First results of a study on attitudes, services, success and barriers in practice [Herz-Kreislauf-Prävention beim Hausartz? Erste Ergebnisse einer Studie zu Einstellungen, Angeboten, Erfolgen und Problemen in der Praxis]. Dtsch Med Wochenschr, $137,17-22$.

13 Van Driel, M. L., De Sutter, A. I., Christiaens, T. C. M. \& De Maesenaar, J. M. (2005) Quality of care: the need for medical, contextual and policy evidence in primary care. Journal of Evaluation in Clinical Practice, 11, 417-429.

14 Kitzinger, J. (1995) Qualitative research. Introducing focus groups. BMJ (Clinical Research Ed.), 311, 299-302. 
Vos, H.M.M., Adan, I.M.A., Schellevis, F.G., Lagro-Janssen, A.L.M. Prevention in primary care: facilitators and barriers to transform prevention from a random coincidence to a systematic approach. Journal of Evaluation in Clinical Practice: 2014, 20(3), 208-215

\section{TABLES}

Table 1 Characteristics of the witnesses, September 2011

\begin{tabular}{|c|c|}
\hline Sex & Function (in the past) \\
\hline Male & $\begin{array}{l}\text { Board member and head of guideline development } \\
\text { department of the college }\end{array}$ \\
\hline Male & Board member of the association \\
\hline Male & Board member of the college and researcher \\
\hline Male & $\begin{array}{l}\text { Team leader prevention and education of patients of the } \\
\text { college }\end{array}$ \\
\hline Male & $\begin{array}{l}\text { Researcher and involved in the project Prevention: } \\
\text { tailor-made }\end{array}$ \\
\hline Male & Head of guideline development department of the college \\
\hline Male & Board member of the association and of the college \\
\hline Female & Minister of Health \\
\hline
\end{tabular}

Table 2 facilitators and barfiers characterizing the first stage of implementing prevention (roughly 1985-1993). Thirty-three main codes were identified and were grouped into the four main categories

\begin{tabular}{|c|c|c|}
\hline & Facilitators & Barriers \\
\hline Social context & $\begin{array}{l}\text { - Influence from politicians, policy makers and pharmaceutical companies } \\
\text { - Associations of GPs working well together } \\
\text { - Strategic motives, such as ICT, positioning the GP and primary care }\end{array}$ & \\
\hline $\begin{array}{l}\text { Professional } \\
\text { context }\end{array}$ & $\begin{array}{l}\text { - Reasonable scientific evidence based on literature } \\
\text { - Corresponding to daily practice and existing pilots } \\
\text { - Position and responsibility: prevention should be for everyone (equity) and } \\
\text { is a part of primary care } \\
\text { - Atmosphere: quietness in the profession }\end{array}$ & $\begin{array}{l}\text { - Scientific evidence: difficulty to meet } \\
\text { the criteria of Wilson and Jungner } \\
\text { - Position and responsibility: prevention is } \\
\text { not a part of primary care } \\
\text { - Atmosphere: agitation in the profession }\end{array}$ \\
\hline $\begin{array}{l}\text { Organizational } \\
\text { context }\end{array}$ & - Sufficient logistic and practical support and finances & \\
\hline Personal motives & $\begin{array}{l}\text { - Personal motives: PhD thesis on prevention and little resistance from an } \\
\text { influential opponent }\end{array}$ & \\
\hline
\end{tabular}

GP, general practitioner.

Table 3 Facilitators and barriers characterizing the second stage of implementing prevention (1993-1999). Twenty-three main codes were identified at this stage and were grouped into the four main categories

\begin{tabular}{|c|c|c|}
\hline & Facilitators & Barriers \\
\hline Social context & $\begin{array}{l}\text { - Pressure to screen people of } 60 \text { and over by the funder of the research } \\
\text { - Unity in the associations of GPs } \\
\text { - Use of ICT, stronger position of GP and prevention to acquire support }\end{array}$ & \\
\hline $\begin{array}{l}\text { Professional } \\
\text { context }\end{array}$ & $\begin{array}{l}\text { - Scientific evidence: CVRM pilots work, theoretical } 50 \% \text { reduction of risk, } \\
\text { guidelines are already evidence based } \\
\text { - Corresponding to daily practice: guidelines were not new } \\
\text { - Less discussion because CVRM is secondary prevention and an improvement } \\
\text { of care }\end{array}$ & $\begin{array}{l}\text { No scientific evidence for primary } \\
\text { prevention CVD }\end{array}$ \\
\hline $\begin{array}{l}\text { Organizational } \\
\text { context }\end{array}$ & $\begin{array}{l}\text { - Facilitating prerequisites: sufficient logistic and practical support and finances } \\
\text { - Large group of people with risk for CVD }\end{array}$ & $\begin{array}{l}\text { The application of measuring blood pressure } \\
\text { in all people of } 60 \text { and over is suspect }\end{array}$ \\
\hline Personal motives & PhD was motivated to implement PhD subject & \\
\hline
\end{tabular}

CVD, cardiovascular disease; CVRM, cardiovascular risk management; GP, general practitioner. 
Vos, H.M.M., Adan, I.M.A., Schellevis, F.G., Lagro-Janssen, A.L.M. Prevention in primary care: facilitators and barriers to transform prevention from a random coincidence to a systematic approach. Journal of Evaluation in Clinical Practice: 2014, 20(3), 208-215

Table 4 Facilitators and barriers characterizing the third stage of implementing prevention (1999-2000). Fifteen main codes were identified in this stage and were grouped into three main categories

\begin{tabular}{|c|c|c|}
\hline & Facilitators & Barriers \\
\hline Social context & $\begin{array}{l}\text { - Advice from the college to start with CVRM } \\
\text { - Pressure to proceed under the condition that } \\
\text { more research would follow on screening }\end{array}$ & $\begin{array}{l}\text { - Tension within the profession and between the two associations } \\
\text { - Cancelling CVRM as a signal to the Ministry of Health and creating an } \\
\text { enemy to obtain unity in the profession }\end{array}$ \\
\hline $\begin{array}{l}\text { Professional } \\
\text { context }\end{array}$ & A successful pilot in 1000 GP practices & $\begin{array}{l}\text { - Insufficient scientific evidence to persuade the GPs } \\
\text { - Hesitation to start with another prevention theme }\end{array}$ \\
\hline $\begin{array}{l}\text { Organizational } \\
\text { context }\end{array}$ & & $\begin{array}{l}\text { Insufficient payment and tension about reimbursement of the implementation } \\
\text { of practice nurses }\end{array}$ \\
\hline
\end{tabular}

CVRM, cardiovascular risk management; GP, general practitioner.

Table 5 Facilitators and barriers characterizing the fourth stage of implementing prevention (2000-present). Forty-five main codes were identified in this stage and were grouped into three main categories

\begin{tabular}{|c|c|c|}
\hline & Facilitators & Barriers \\
\hline Social context & $\begin{array}{l}\text { - Funds started with check-ups and requested guidelines } \\
\text { - Associations of GPs started to cooperate again } \\
\text { - Strategic motives: bringing prevention back by means of } \\
\text { revision of guidelines } \\
\text { - Influence from patients }\end{array}$ & $\begin{array}{l}\text { - Differences of opinion between GPs and funds } \\
\text { - Insurance companies did not support prevention as a cost } \\
\text { effective way to keep people healthy } \\
\text { - A cold war between the associations of GPs } \\
\text { - Strategic motives: no focus on prevention }\end{array}$ \\
\hline $\begin{array}{c}\text { Professional } \\
\text { context }\end{array}$ & $\begin{array}{l}\text { - Scientific evidence was partly present and when not present } \\
\text { it was postponed } \\
\text { - Guidelines were already there, with CVRM an entrance to } \\
\text { the guidelines was created } \\
\text { - Responsibility to offer prevention, equity, the GP as a coach }\end{array}$ & $\begin{array}{l}\text { - Scientific evidence: trials were unethical, insufficient } \\
\text { evidence, harder to obtain evidence in prevention } \\
\text { - Updating guidelines took all the time, no time left for } \\
\text { prevention } \\
\text { - The GP had to learn people to deal with risk instead of } \\
\text { screening }\end{array}$ \\
\hline $\begin{array}{l}\text { Organizational } \\
\text { context }\end{array}$ & $\begin{array}{l}\text { - Finances were present } \\
\text { - An international guideline became a primary care guideline in } \\
\text { the Netherlands } \\
\text { - The nature of CVRM: screening is non-invasive }\end{array}$ & $\begin{array}{l}\text { - Only the check-up is reimbursed, the rest is not } \\
\text { - Insurances companies abuse prevention programmes for } \\
\text { marketing rather than improving health }\end{array}$ \\
\hline
\end{tabular}

CVRM, cardiovascular risk management; GP, general practitioner. 